\title{
Sekilas Tentang Manik-Manik Kemiling, Punggunghardjo, Lampung Tengah
}

\section{Rita Istari}

Keywords: beads, artifact, description, typology, sumatra

\section{How to Cite:}

Istari, R. Sekilas Tentang Manik-Manik Kemiling, Punggunghardjo, Lampung Tengah. Berkala Arkeologi, 16(1), 25-32. https://doi.org/10.30883/jba.v16i1.743

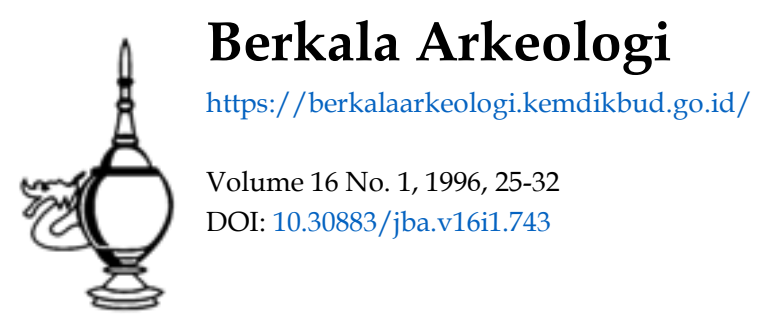

\section{(@) $\odot \Theta \odot$}

This work is licensed under a Creative Commons Attribution-NonCommercial-ShareAlike 4.0 International License. 


\title{
SEKILAS TENTANG MANIK-MANIK KEMILING, PUNGGUNGHARDJO, LAMPUNG TENGAH
}

\author{
TM. Rita Istari \\ (Pusat Penelitian Arkeologi Nasional)
}

\section{Penalaran}

Penelitian kepurbakalaan di situs Punggungharjo dan sekitarnya telah banyak dilakukan. Masalah utama yang menarik untuk diamati dari situs ini adalah peninggalan tradisi megalitik dan suatu benteng dari gundukan tanah setinggi kurang lebih 2 - 3,5 meter. Bentuk benteng melingkar dengan bahan tanah biasa. Menarik perhatian, di dalam benteng tersebut terdapat suatu tempat yang disebut sebagai kompleks "batu mayat" yang terdiri dari batu altar, menhir, batu berdiri dan sebuah batu datar bergores. Di samping itu, terdapat temuantemuan lepas seperti pecahan gerabah, keramik asing dan manikmanik. Di luar benteng tidak dijumpai satu temuan pun baik dari periode prasejah atau pun klasik, sehingga untuk sementara dapat disimpulkan bahwa keaktifan kehidupan masyarakat masa lalu berada di bagian dalam benteng (Sukendar, 1979:16).

Secara administratif, situs Punggungharjo terletak di Kecamatan Jabung, Kabupaten Lampung Tengah. Situs ini pertama kali ditemukan oleh seorang transmigran Jawa yang bernama Bapak Sardi. Penelitianpenelitian yang selama ini dilakukan baik secara survei maupun ekskavasi di situs Punggungharjo umumnya untuk menginventarisasi peninggalan tradisi megalitik, pemukiman, pola penguburan, dan pemujaan (Marsudi,1993:2). Penelitian tahun 1973 yang dilakukan oleh tim gabungan Lembaga Purbakala dan Peninggalan Nasional bekerjasama dengan Pennsylvania Museum University, berhasil ditemukan Situs Punggungharjo dan Situs Lebak Ranji, Palembang. Selanjutnya tahun 1993, penelitian dilanjutkan oleh Pusat Penelitian Arkeologi Nasional. Penelitian ini dilakukan sehubungan dengan adanya laporan penduduk atas penemuan manik-manik dalam jumlah banyak dan batu-batuan lepas (Marsudi, Ibid, 3).

Dalam tulisan ini kajian akan dipusatkan pada keberadaan manikmanik, khususnya yang ditemukan di salah satu gundukan tanah di Dukuh Kemiling, Desa Punggungharjo. Banyaknya temuan manikmanik dan calon manik-manik di situs ini menarik untuk dikaji, di samping itu ditemukan juga bata yang berangka tahun $1325 \mathrm{M}$. 
Bertolak dari data di atas, permasalah yang ingin dikaji dalam tulisan ini adalah mengapa manik-manik ditemukan dalam jumlah yang begitu banyak? Apakah manik-manik itu memiliki fungsi upacara atau penguburan? Kedua, mengapa di situs tersebut disamping ditemukan manik-manik, juga terdapat bahan manik-manik dan manik-manik yang belum jadi. Apakah manik-manik itu digunakan dalam upacara hanya secara disebar (ditaburkan) ke bagian puncak gundukan tanah yang biasanya dianggap perwujudan dari gunung? Ketiga, apakah fungsi dari gundukan tanah, lokasi manik-manik ditemukan?

Data yang terdapat di situs Kemiling ini sangat menarik karena merupakan temuan pertama di Indonesia berdasarkan jumlah manikmanik serta konteksnya yang diperkirakan sebagai tempat keramat pada masa lalu. Sehubungan dengan hal itu, kajian ini dimaksudkan untuk merekontruksi tentang peranan dan fungsi manik-manik, bahwa tinggalan ini tidak hanya dipergunakan sebagai bekal kubur atau berkaitan dengan keperluan estetis, melainkan juga berkaitan dengan fungsi upacarta-upacara pemujaan.

\section{Data tentang manik-manik dan temuan lainnya.}

Dalam penelitian di situs Kemiling ini dilakukan ekskavasi sebanyak empat kotak. Letak kotak galian ditentukan berdasarkan tujuan menjajagi sebaran manik-manik yang banyak ditemukan dan tersebar di permukaan tanah.

Di situs Kemiling yang merupakan kebun jagung dan tanaman coklat, dijumpai sebuah gundukan tanah yang berbentuk kerucut. Beberapa batu bata ditemukan di sana-sini sebagai penyangga agar tanah tidak longsor. Batu bata di situs ini berukuran cukup besar dan bervariasi yaitu panjang $18.45 \mathrm{Cm}$, lebar $18.22 \mathrm{Cm}$, tebal $7.8 \mathrm{Cm}$. Jenis bahan dari batu tersebut juga berbeda, yaitu: tufa, aluvial abu-abu dan aluvial coklat merah. Batu bata abu-abu yang bahannya dari aluvial abu-abu plastis sebagai hasil batuan tufa, dalam pengerjaannya tidak dilakukan percampuran bahan lain, tetapi murni dari bahan aluvial abu-abu plastis kemudian dibakar. Batu bata merah bahannya dari aluvial coklat merah sebagai hasil pelapukan batuan batuan beku, dalam pengerjaannya dilakukan percampuran antara aluvial coklat merah dengan batu pasir tufaan, kemudian dibakar (Marsudi dkk, 1993:23-24). Sedangkan tinggi gundukan lebih kurang $174 \mathrm{Cm}$. Dari dataran sekelilingnya, luas bukit kecil tersebut sekitar 100 meter persegi. Sebelum digali pada bagian atas gundukan, ditemukan manik- 
manik yang tersebar dengan bentuk bulat pipih dan berwarna kuning. coklat, hijau dan putih.

Hasil ekaskavasi dengan sistem kotak (box system) telah diperoleh data tentang manik-manik sebagai berikut: Temuan manikmanik dominan berwarna kuning, bahan sebagian besar terbuat dari kaca dan sedikit terbuat dari tanah (clay). Sebagian besar manik-manik itu berbentuk bulat (oblate) dan dibuat dengan teknik tarik (drawnbeads), karena ada beberapa manik-manik yang tidak terpotong dengan baik (segmented). Adapun teknik pembuatan dengan teknik tarik (drawn beads) itu sebagai berikut: Mula-mula serbuk dari bahn kaca dipanaskan sampai menjadi cair dan lembek. Cairan kaca tersebue diambil dengan menggunakan dua buah tongkat, kemudian kedua tongkat tersebut ditarik ke arah berlawanan, sehingga cairan itu berbentuk memanjang. Sesudah cairan mendingin, kemudian dipotong-potong sesuai dengan bentuk dan besar manik-manik yang dikehendaki. Terkadang pemotongan kurang sempurna, mengakibatkan bentuk tidak bagus bahkan tidak terpotong.

\section{Pembahasan}

Terbatas dari hasil penelitian di situs Kemiling belum cukup untuk dilakukan kajian. Oleh karena itu sebagai data pembanding dilakukan juga survei di sekitar wilayah Pugungraharjo. Hasil survei kepurbakalaan di sekitar Taman Purbakala memperlihatkan adanya peninggalan masa prasejarah dan masa Hindu-Budha hal ini menimbulkan pertanyaan apakah situs tersebut merupakan situs klasik atau masa pengaruh Hindu-Budha. Hal ini menimbulkan pertanyaan, apakah situs tersebut merupakan situs klasik. Fenomena yang tampak di situs tersebut kemungkinan merupakan sautu perpaduan tradisi berlanjut megalitik yang berlanjut pada masa klasik, namun hal ini masih perlu dikaji lebih lanjut.

Pada situs Kemiling, temuan yang berupa gundukan tanah menimbulkan tanda-tanya. Jika ditinjau dari konsep kepercayaan masa prasejarah, maka peningalan ini dapat dikelompokkan sebagai hasil budaya prasejarah. Gundukan tanah dapat diidentifikasi sebagai gunung yaitu tempat keramat yang dianggap merupakan tempat arwah leluhur. Di samping itu, gunung memegang peranan, sebagai orientasi arah hadap suatu megalit, dilain pihak unsur-unsur yang melekat pada konsep kepercayaan Hindu tampak juga. Dengan demikian apakah tidak mungkin terdapat inkulturasi, yaitu perpauan dua kebudayaan 
antara unsur kebudayaan yang satu akan menambah dan memperkaya unsur kebudayaan yang lain.

Hasil ekskavasi situs Kemiling pada tahun 1993, menunjukkan bahwa gundukan tanah di situs tersebut memang sengaja dibuat sedemikian rupa oleh masyarakat pendukungnya. Kesengajaan membuat bentuk seperti gunung pada masa itu dilandasi oleh konsepsi tradisi megalitik yang bersumber pada pemujaan arwah nenek moyang. Dalam konsep Hindu kepercayaan itu menjadi keyakinan adanya kepercayaan kepada atman. Kepercayaan adanya roh dan kekuatan-kekuatan gaib biasanya dihubungkan dengan suatu tradisi pembuatan bangunan teras berundak, menhir atau tahta batu. Menhir dianggap merupakan simbol dari keuatan gaib dan simbol kelelakian. Menhir juga merupakan sarana pemujaan roh nenek moyang, dan sring dianggap sebagai simbol keberadaan kepala suku atau seorang tokoh masyarakat. Sedangkan teras berundak merupakan simbol dari gunung yang dianggap suci dan keramat. Ada kepercayaan roh itu bersemayam di atas gunung. Masyarakat yang mempunyai kepercayaan semacam ini tidak lepas dari suatu pemahaman, bahwa hasil-hasil arsitek dalam bentuk bangunan adalah sesuatu yang dibuat manusia dalam kehidupannya waktu itu, untuk dijadikan sarana perlindungan demi kepentingan badan maupun keselamatan jiwanya (Djauhari, 1978:3). Oleh karena itu, khusus bangunan teras dari tanah di Dukuh Kemiling dalam kaitannya dengan manusia-manusia pendukungnya jelas sebagai usaha dan langkahlangkah manusia untuk memohon kesejahteraan, perlindungan, kesuburan dan lain-lain. Hal ini tentunya tidak berbeda jauh dengan pengertian arsitektur masa kini. Bangunan bagi manusia bertujuan untuk mencari dan memperoleh keamanan dan kenyamanan diri demi kesejahteraan, perlindungan dan kesuburan sekaligus memenuhi kepuasan diri dalam mencipta sesuatu keindahan. Sebagai hasil cipta karya kebudayaan, wujud arsitektur dipengaruhi oleh beberapa unsur. Unsur unsur tersebut ialah berkaitan dengan geografis, kemasyarakatan, agama maupun falsafah kepercayaan serta latar belakang sejarah yang nantinya akan mempengaruhi bentuk serta gaya bangunan yang dihasilkan.

Gundukan tanah berbentuk kerucut di Kemiling dalam agama Hindu, tampaknya dapat dihubungkan dengan "dewa gunung" yang oleh Quaritch Wales dikatakan sebagai "The Mountain of God" Wales, 1958: 91). Dalam agama Hindu maupun prasejarah gunung tetap memegang peranan penting. Dengan demikian, maka jelas bahwa baik dalam masa prasejarh maupun masa perkembangan agama Hindu gundukan tanah di situs Kemiling, merupakan tempat penting 
Dalam hal ini kemungkinan besar bangunan tersebut dipergunakan dalam kaitannya dengan peribadatan, yaitu usaha untuk mendekatkan diri dengan zat tertinggi (supranatural). Gundukan tanah berbentuk kerucut dianggap sebagai suatu tempat suci sebagai simbol dari gunung. Oleh karena itu, maka teras dari tanah yang diperkuat dengan batu bata tersebut merupakan tempat para pemujanya berlumpul dan di sanalah manik-manik itu berfungsi.

Sebagaimana telah disinggung di atas, bahwa manik-manik dalam masa prasejarah biasanya ditemukan bersama-sama rangka manusia. Seperti di situs Plawangan, Gilimanuk, Melolo dan lain-lain. Manik-manik di situs Kemiling dari hasil ekskavasi tidak ditemukan bersama rangka. Kenyataan ini menimbulkan suatu pertanyaan. Dalam hubungannya dengàn tempat-tempat kubur, seperti kubur batu, kubur tempayan, kubur-kubur dalam gua dan lain-lain jelas manik-manik sebagai sarana yang dikuburkan bersama mayat agar arwah si mayat dapat memperoleh kedudukan fungsi di tempat arwah bersemayam. Tetapi di sini jelas, bahwa manik-manik bersama bahan, dan manikmanik setengah jadi mempunyai fungsi berbeda, yaitu sebagai sarana upacara yang bukan penguburan.

Temuan pada permukaan tanah berupa beberapa potong batu persegi panjang dari bahan bata dan tufa yang nampak sebagai hasil buatan tangan manusia. Tetapi setelah diadakan ekskavasi pada kedalaman kurang lebih dua meter dari puncak bukit tidak ditemukan batu-batu bangunan lainnya, apalagi struktur bangunan yang berhubungan dengan batu-batu bangunan dari temuan permukaan tanah.

Selanjutnya pada salah satu batu tufa yang berukuran panjang 38 $\mathrm{Cm}$, lebar $16 \mathrm{Cm}$ dan tebal $9 \mathrm{Cm}$ yang ditemukan di atas permukaan tanah, didapatkan tulisan menunjukkan angka tahun 1247 Caka atau 1325 Masehi. Berarti di situs tersebut pernah berlangsung aktivitas pada sekitar abad XIII - XIV Masehi. Hanya yang menjadi permasalahan adalah batu bertulis itu insitu atau tidak, mengingat bahwa di tempat tersebut tidak ada temuan lain sebagai pendukung yang berhubungan dengan batu bertulis tersebut.

\section{Penutup}

Hasil ekskavasi di situs Kemiling memperlihatkan bahwa manikmanik ditemukan secara konsentrasi di bagian tangah teras tanah. Dengan demikian kemungkinan aktivitas manusia terdapat di bagian tengah gundukan tanah terebut. Bahan manik-manik sebagian besar terbuat dari bahan kaca, baik bentuk maupun warnanya sangat 
bervariasi (Haris, 1985:38). Manik-manik tersebut bercampur dengan temuan berupa kelintingan kecil-kecil terbuat dari bahan perunggu dalam jumlah yang cukup banyak. Dalam konteks ini yang penting dipertanyakan ialah apakah kelintingan dan manik-manik itu merupakan satu rangkaian ataukah keduanya memiliki fungsi sendirisendiri? Sebagai data pembanding, manik-manik dan kelintingan merupakan satu rangkaian, dapat dilihat dalam The History of Beads, bahwa pernah ditemukan seuntai kalung atau semacam perhiasan sebagai kostum pelengkap upacara yang dipergunakan oleh suku bangsa Naga, Konyak, India. Kalung tersebut berupa rangkaian manikmanik bahan dari kaca dominan berwarna kuning yang dikombinasikan dengan kelintingan kecil dari perunggu, sedangkan manik-manik dari bahan emas, moluska dan kelintingan tersebut jelas merupakan sarana upacara tertentu yang berfungsi sama. Dalam hal ini kemungkinan manik-manik yang junlahnya banyak bersama manikmanik setengah jadi dan kelintingan kecil-kecil ditaburkan di atas gundukan tanah dengan sengaja.

Beberapa hal yang penting diperhatikan dari lokasi-penetitian ini antara lain dalam hubungannya dengan masalah yang diajukan adalah sebagai berikut.

4.1. Temuan berupa beberapa potong batu persegi dan yang sebuah di antaranya bertulisan angka tahun 1247 Saka, ada hubungannya dengan keberadaan bangunan yang pernah ada di sana. Angka tahun di batu bata tersebut dapat dipergunakan sebagai data awal berkenaan dengan umur bangunan tersebut, yakni sezaman dengan kerajaan Majapahit.

4.2. Berkenaan dengan jumlah penemuan manik-manik dan persebaran-nya, kemungkinan terjadi pada masa setelah tradisi megalitik berkembang atau kemungkinan justru pada masa berkembangnya pengaruh Hindu. 
Djauhari Sumintardja. 1978 Kompedium Sejarah Arsitektur I Bandung: Yayasan Lembaga Penyelidikan Masalah Bangunan.

Louis Sherr Dubin.1987. The History of Beads. London: Thames and Hudson Ltd.

Marsudi Utomo,dkk.1993. Laporan Penelitian Arkeologi Bidang Arkeometri. Penelitian di situs Kemiling, Desa Punggungraharjo, Kecamatan Perwakilan Sekampung Udik, Kabupaten Lampung Tengah, Propinsi Lampung.

Sukendar, Haris. Laporan Penelitian Kepurbakalaan di Lampung. Berita Penelitian Arkeologi No. 20. Jakarta: Puslitarkenas.

...-.... 1985 Laporan Penelitian Kepurbakalaan di Lapung. Berita Penelitian Arkeologi No. 33. Djakarta, PuslitArkenas.

Wales, Quaritch,H.G.1958. The Mountain of god. London, Bernard LTD 


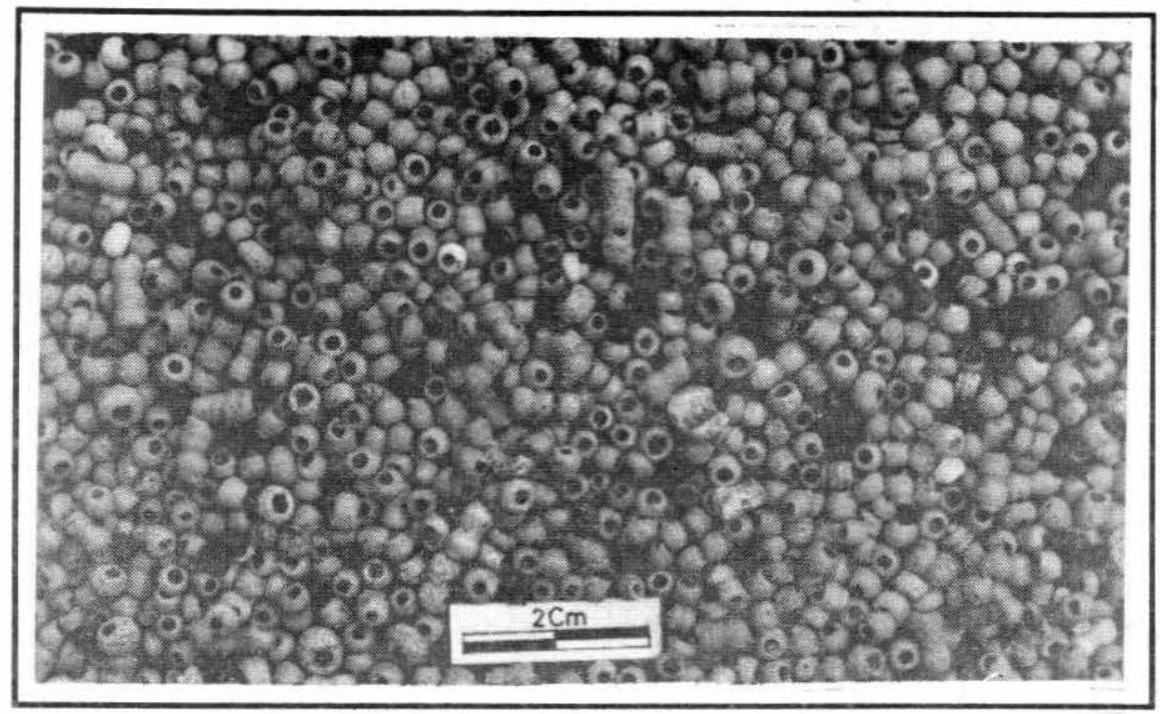

Foto 1 : Manik-manik dari situs Kemiling

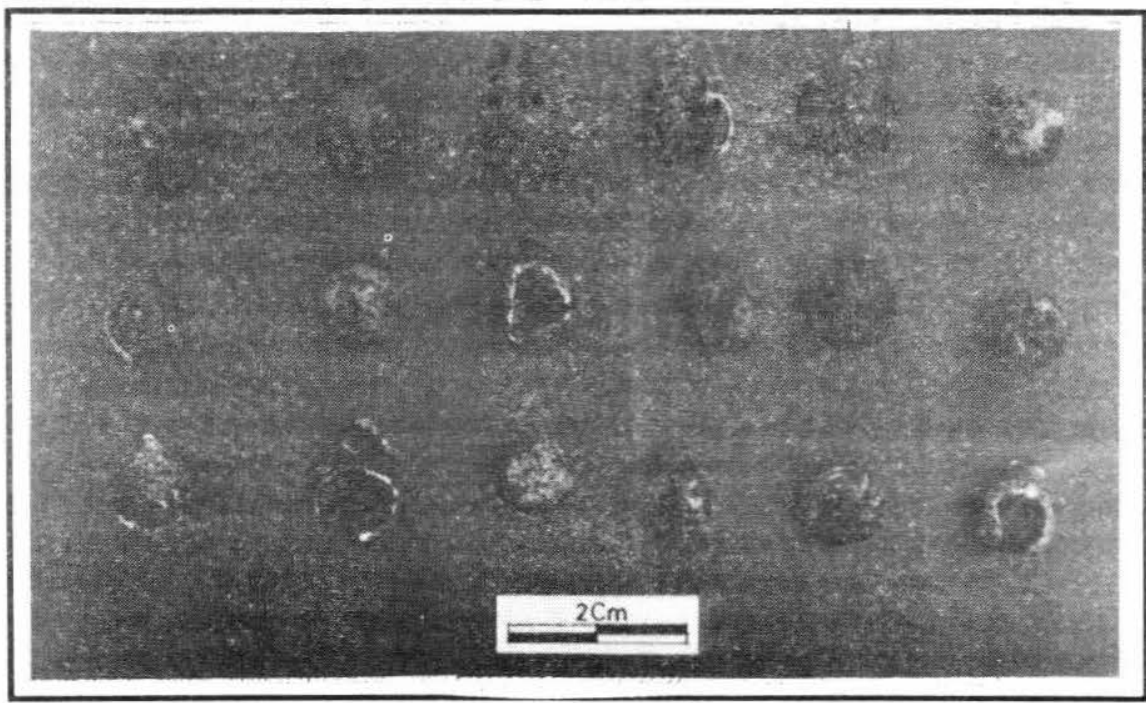

Foto 2 : Kelintingan dari perunggu 